\title{
Mathematical Modeling of Solidification Microstructure of Pure Copper by Vacuum Continuous Casting and Its Experimental Verification
}

\author{
De-Chang TSAI, ${ }^{1)}$ Man-Shan HSU, ${ }^{1)}$ Weng-Sing HWANG ${ }^{1)}$ and Cheng-Syue JIANG ${ }^{21}$ \\ 1) Department of Materials Science and Engineering, National Cheng Kung University, No. 1 Ta-Hsueh Road, Tainan 701 \\ Taiwan. E-mail: wshwang@mail.ncku.edu.tw 2 2) Metal Industries Research \& Development Centre, Kaohsiung 81160 \\ Taiwan.
}

(Received on March 26, 2010; accepted on July 27, 2010)

\begin{abstract}
The purpose of this study is to predict the solidification microstructure of pure copper rod by vacuum continuous casting (VCC) process and verify its accuracy by experimental observation. This study was extended from previous study (using 2D-CA model). A three dimensional cellular automaton (3D-CA) model and the finite difference method were utilized to simulate the macro-temperature field, nucleation, and grain growth of a pure copper rod based on the actual casting operations. The simulated solidification microstructures obtained from the 3D-CA model were found in good agreement with the results of actual casting experiments. Both numerical simulations and experimental observations show that the microstructure of a copper rod changes with casting speed and that the $S / L$ interface moves closer to the orifice of the mould with increasing drawing speed.
\end{abstract}

KEY WORDS: oxygen-free copper; vacuum continuous casting; solidification microstructure; three dimensional cellular automaton; numerical simulation.

\section{Introduction}

Copper is widely employed in thermal components and electrical wiring due to its excellent properties such as good formability and corrosion resistance. Recent advancements in technology are demanding smaller and thinner electronic devices which require slimmer and more delicate wiring systems. This decrease in wire dimensions requires materials that have better mechanical properties for fine-drawing while remaining reasonably conductive and corrosion-free. To meet the required specifications, the purity level for ultra-high purity copper has been increased from the 3 and $4 \mathrm{~N}$ levels to the $6 \mathrm{~N}$ level. ${ }^{1)}$ Vacuum Continuous Casting (VCC) is one of the main methods used to produce copper rods. After further mechanical processing such as drawing, wires and tubes with high purity and homogeneity can be directly applied to various devices.

Solidification is the most important process in VCC. It determines the formation of the bulk microstructure, which is directly related to the mechanical and chemical properties. In the VCC process, various casting conditions such as casting speed are manipulated, which in turn affect the temperature gradient and growth rate, to control the microstructure formation during solidification and thus improve the specified properties. Earlier studies were conducted on the basis of physical observation and metallurgical analysis on actual casts under various operating conditions. Although viable, these methods involve a lot of man- power, resources, and time. It is thus desirable to utilize numerical modeling techniques to simulate the solidification microstructure. Using numerical simulation, predictions can be made for microstructural changes with respect to casting conditions.

Two major methods can be used to model cast microstructure, deterministic and probabilistic. The deterministic method is based on the kinetics of solid-state transformation during solidification, with nuclei density and growth rate considered as a function of undercooling. Oldfield (1966) associated heat transfer with grain growth to simulate the crystallization of grey iron, in which nucleation changes constantly in proportion to the square of undercooling. ${ }^{2)}$ Hunt (1984) published a model for instantaneous nucleation in continuation with applying the deterministic methods. ${ }^{3)}$ In terms of categorizing the crystals formed, Dunstin and Kurz assumed the growth of spherical, columnar, and cylindrical equiaxed grains. ${ }^{4)}$ Their revised method focused on simulating the number of grains and average grain size in several zones of interest. Although the deterministic method is derived from solidification kinetics and physically satisfies conditions for grain growth, it fails to consider heat flow and the general randomness of the nucleation process. Effects such as grain distribution and growth direction are therefore disregarded, which greatly limits the predictions on the overall grain morphology and grain intrusions. Moreover, since the grain shape is decided in advance, the deterministic model cannot express the transfor- 
mation of grain morphology (CET or ECT).

These limitations can be overcome by applying the Monte Carlo method developed by Brown and Spittle, also known as the probabilistic model. ${ }^{5)}$ This method adopts the principles of the lowest surface energy of grains and combines them with random selection to address nucleation, grain growth, and solid-liquid phase transformation for metals. The results are reasonably similar compared to a real cast product; however, there is a lack of physical meaning of dendritic growth dynamics.

More recently, emphasis has been put on integrating the advantages of the two models. Rappaz and Gandin developed a Cellular Automation (CA) method based on the heterogeneous nucleation and the continuous nucleation models. $^{6-9)}$ The continuous nucleation model integrates the Gaussian distribution between nucleation densities and undercooling. In the CA model, nucleation locations and preferential growth orientation are determined using the probabilistic model, whereas the growth rate of dendrite tips is modeled with the deterministic model based on physics theories. Therefore, the CA method combines the advantages of the Monte Carlo method with the physical meanings of crystallographic effects and grain selection. Furthermore, Zhu and Hong have developed a CA method that can simulate microstructure evolution during eutectic and peritectic solidification. ${ }^{10)}$ Some modified CA models that directly solve the transport equations at the solid-liquid interface have been developed to simulate dendritic growth patterns. ${ }^{11)}$ Further developments of the CA model are coupling the phase-field method (PF-CA model) for the simulation of formation of macrostructures in multi-component alloy systems. ${ }^{12)}$ The effect of macrosegregation also has been developed to account for structure formation compared to purely macroscopic models. ${ }^{13)}$

In the present study, a microstructure prediction system for the VCC process based on the Cellular Automaton (CA) model is developed. The system is then tested by comparing the actual cast observations with simulation results for the effects of casting speed on microstructural changes of copper.

\section{Experimental Method}

The proposed study adopted the VCC process to fabricate copper rods. In the VCC process, a vacuum furnace and continuous casting techniques are used to produce high cleanliness and purity products. The vertical casting direction enables symmetrical cooling and homogeneous microstructure formation. The equipmental set up is shown in Fig. 1. The experimental parameters used in this study are shown in Table 1. Graphite moulds and crucibles made of carbon IG15 were used for the VCC process. As shown in Fig. 2, the mould was $2 \mathrm{~cm}$ in diameter and $10 \mathrm{~cm}$ in height, and the crucible was $20 \mathrm{~cm}$ in diameter and $25 \mathrm{~cm}$ in height. A typical experimental procedure began with the vacuum smelting of pure copper at a pressure of $1.0 \times 10^{-4} \mathrm{~atm}$ and the carbon crucible being preheated to $1250^{\circ} \mathrm{C}$. Drawing was conducted at various casting speeds under a nitrogen atmosphere, with a cooling water flow rate of $20 \mathrm{~L} / \mathrm{min}$, resulting in a copper rod with a diameter of $8 \mathrm{~mm}$. The temperature profiles at various locations on the sample were

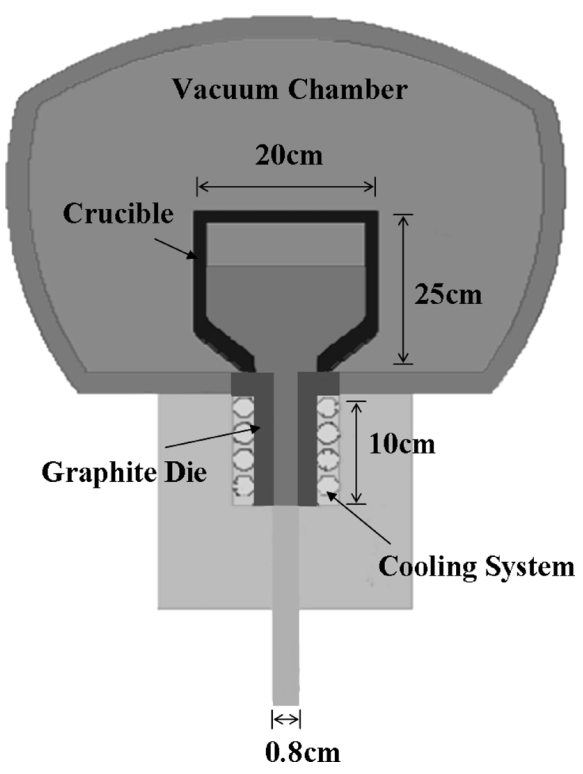

Fig. 1. Illustration of VCC equipment.

Table 1. Experimental parameters of VCC process

\begin{tabular}{|c|c|c|c|c|c|}
\hline $\begin{array}{c}\text { Casting } \\
\text { material }\end{array}$ & $\begin{array}{c}\text { Crucible } \\
/ \text { mold }\end{array}$ & $\begin{array}{c}\text { Preheat } \\
\text { temperature } \\
\left({ }^{\circ} \mathrm{C}\right)\end{array}$ & $\begin{array}{c}\text { Vacuum } \\
\text { pressure } \\
(\mathrm{atm})\end{array}$ & $\begin{array}{c}\text { Cooling } \\
\text { water } \\
(\text { liter/min })\end{array}$ & $\begin{array}{c}\text { Casting } \\
\text { speed } \\
(\mathrm{mm} / \mathrm{min})\end{array}$ \\
\hline copper & graphite & 1250 & $1.0 \times 10^{-4}$ & 20 & $100 \sim 800$ \\
\hline
\end{tabular}

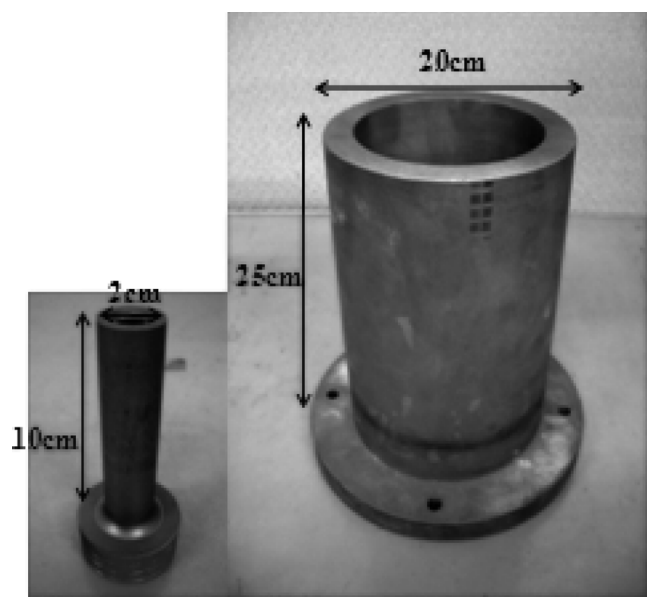

Fig. 2. Photograph of graphite mould and crucible used in VCC process.

measured and recorded throughout the experiment. The casting was cut into multiple sections and embedded in epoxy-based modules. Grinding, polishing, and etching with nitric acid (etching time of $3 \mathrm{~s}$ ) were then performed. An optical microscope was used to observe the microstructures of the copper rod fabricated under various casting conditions.

\section{Numerical Analyses}

The physical model used to develop the numerical simulation in this study is shown in Fig. 3. Liquid metal is shown at the centre and a dummy bar with the diameter of $8 \mathrm{~mm}$ is used to continuously draw copper rod through the graphite mould in a vacuum, with water cooling surround- 


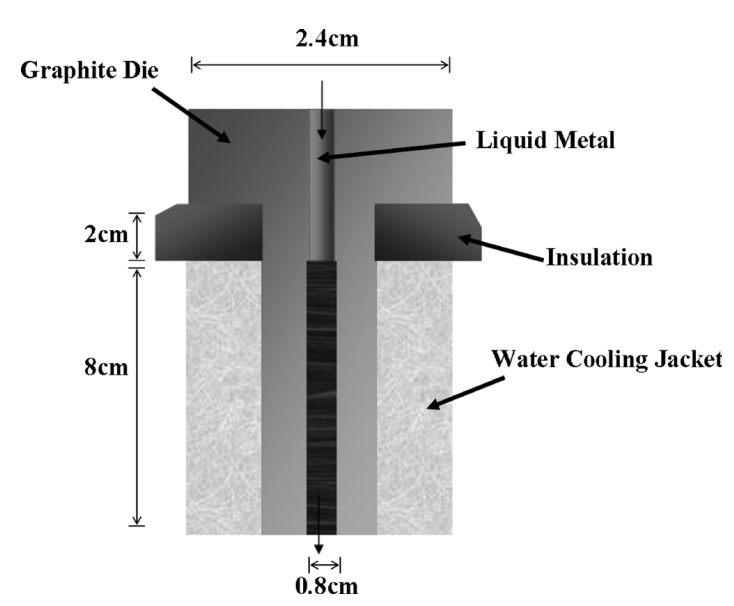

Fig. 3. Sketch of the physical model for VCC process.

ing the model. The length of the cooling system and insulation is 8 and $2 \mathrm{~cm}$, respectively. The related numerical simulation methods are described below.

\subsection{Heat Flow Calculation in VCC Process}

In the present simulation, the finite difference method was used to calculate transient heat transfer in the VCC process. The governing equation is given by

$$
\rho C_{\mathrm{p}} \frac{\partial T}{\partial t}=\lambda\left(\frac{\partial^{2} T}{\partial r^{2}}+\frac{1}{r} \frac{\partial T}{\partial r}+\frac{\partial^{2} T}{\partial z^{2}}\right)-\rho C_{\mathrm{p}} V_{\mathrm{c}} \frac{\partial T}{\partial z} \dot{q}
$$

where $r$ and $z$ are the grid size with the length of $0.4 \mathrm{~mm}, \rho$ is the density, $C_{\mathrm{p}}$ is the specific heat, $\lambda$ is the thermal conductivity, $V_{\mathrm{c}}$ is the casting speed, and $\dot{q}$ is the latent heat obtained using the temperature recovery method. ${ }^{14)}$ The boundary conditions at the melt/mould interface and the mould/water interface are given by:

Melt/mould:

$$
q=h_{\text {int }}\left(T_{\text {mould }}-T_{\text {melt }}\right)
$$

Mould/water:

$$
q=h_{\mathrm{w}}\left(T_{\text {water }}-T_{\text {mould }}\right)
$$

where $q$ is the heat flux, $T_{\text {melt }}, T_{\text {mould }}$ and $T_{\text {water }}$ are the temperatures of the melt, the mould, and the cooling water, respectively, and $h_{\text {int }}$ and $h_{\mathrm{w}}$ are the interfacial heat coefficients at the melt/mould and the mould/water interfaces, respectively. The governing equation and boundary condition for heat transfer shown in Eqs. (1), (2), and (3) are solved using an explicit difference algorithm.

\subsection{Nucleation and Growth Algorithm}

Nucleation is the dominant stage of microstructural evolution in solidification, which leads to the establishment of the final grain population. From previously mentioned theories, a heterogeneous nucleation model is adopted to explain the nuclei density increase $\mathrm{dn}$ induced by an increase in the undercooling $d(\Delta T)$ according to the following Gaussian distribution:

$$
\frac{d n}{d(\Delta T)}=\frac{n_{\max }}{\sqrt{2 \pi}\left(\Delta T_{\sigma}\right)} \exp \left[-\frac{1}{2}\left(\frac{\Delta T-\Delta T_{\mathrm{N}}}{\Delta T_{\sigma}}\right)^{2}\right] \ldots
$$

The Gaussian distribution is determined by three parameters:

$n_{\max }$ : maximum density of nuclei given by the integral of the Gaussian distribution from $0-\infty$

$\Delta T$ : mean nucleation undercooling, equivalent to the maximum on a distribution curve

$\Delta T_{\sigma}:$ standard deviation of undercooling, equivalent to the width of the distribution curve

Thus, the density of grain $n(\Delta T)$ formed at a certain undercooling $\Delta T$ is given by:

$$
n(\Delta T)=\int_{0}^{\Delta T} \frac{d n}{d(\Delta T)} d(\Delta T)
$$

Certain CA cells would start nucleation when sufficient undercooling is provided. During any time-step, $\delta t$, the temperature of the specimen decreases by an amount, $\delta T$, and thus the undercooling increases by an amount, $\delta(\Delta T)$. The density of new grains which are nucleated within the volume of melt is given by

$$
\delta n=n[\Delta T+\delta(\Delta T)]-(\Delta T)=\int_{\Delta T}^{\Delta T+\delta(\Delta T)} \frac{d n}{d(\Delta T)} d(\Delta T)
$$

Meanwhile, new grain would lead to the increase in grain density, randomly distributed inside the CA cell. $\delta n$ is then multiplied by the total volume of specimen to give the number of grains, $\delta N$, which is divided by the number of cells, $N_{\mathrm{CA}}$ to give the probability of nucleation, $P_{n}$, where $V_{\mathrm{CA}}$ is the volume of cell. During each time step, cells defining the volume of the specimen are scanned and a random number is given $\Psi$ to each one of them $(0 \leqq \Psi \leqq 1)$ CA cells transform from liquid to solid when $\Psi \leqq P_{n}$.

$$
P_{n}=\frac{\delta N}{N_{\mathrm{CA}}}=\delta n V_{\mathrm{CA}}
$$

$P_{n}:$ Probability of nucleation

$\delta N$ : Number of newly formed nuclei

$N_{\mathrm{CA}}$ : Total number of cells

$V_{\mathrm{CA}}$ : The volume of an individual cell

$\delta n$ : The increase of grain density

Once a cell has nucleated, it grows with a preferential direction corresponding to its crystallographic orientation. An algorithm for grain growth with various preferred orientations constructed using three Euler angles was embedded into the CA growth algorithm by Hong. ${ }^{15,16)}$ The algorithm randomly reproduces the preferential $\langle 100\rangle$ growth direction of FCC or BCC metals. Thus, during a time step interval used for integrating the growth kinetics of the dendrite tips, the growth length of the solidified cell $\mathrm{v}$ with respect to its liquid neighbor cell $\mathrm{i}$ (as shown in Fig. 4) is $L_{\mathrm{v}}^{\mathrm{i}}(t)$, which can be calculated using:

$$
L_{\mathrm{v}}^{\mathrm{i}}(t)=W_{\mathrm{v}}^{\mathrm{i}} \cdot \sum_{n=1}^{N}[V(\Delta T) \times \Delta t]
$$

where $\Delta t$ is the time step, $W_{\mathrm{v}}^{\mathrm{i}}$ is the orientation weight coefficient, and $N$ is the iteration number. The orientation weight coefficient $W_{\mathrm{v}}^{\mathrm{i}}$ is given by:

$$
W_{\mathrm{v}}^{\mathrm{i}}=\operatorname{Max}\left[\left|X_{\mathrm{w}}\right|,\left|Y_{\mathrm{w}}\right|,\left|Z_{\mathrm{w}}\right|\right]
$$

where $X_{\mathrm{w}}, Y_{\mathrm{w}}$ and $Z_{\mathrm{w}}$ can be calculated using 


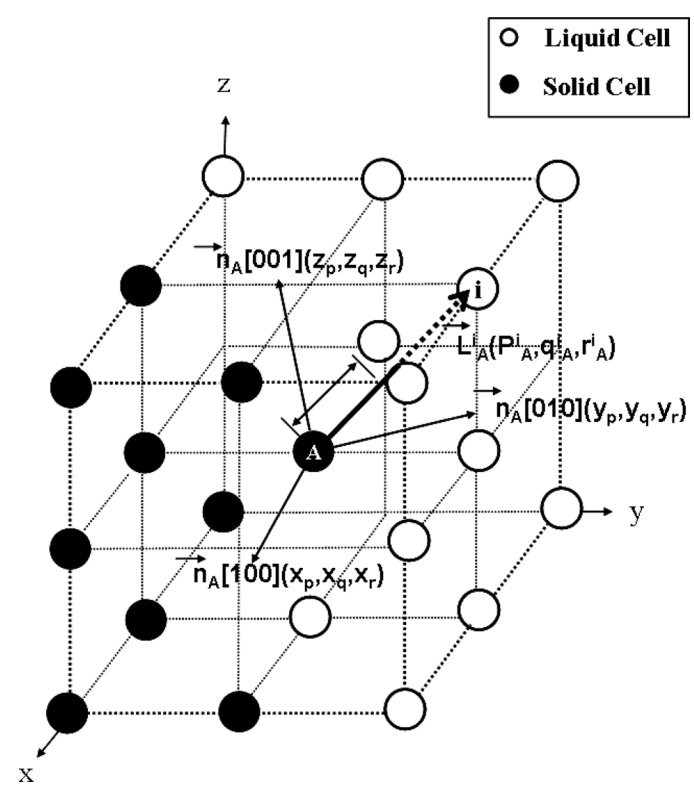

Fig. 4. Schematic diagram of the growth algorithm used in the CA model.

$$
\left[\begin{array}{c}
X_{\mathrm{w}} \\
Y_{\mathrm{w}} \\
Z_{\mathrm{w}}
\end{array}\right]=\left[\begin{array}{c}
x_{p} x_{q} x_{r} \\
y_{p} y_{q} y_{r} \\
z_{p} z_{q} z_{r}
\end{array}\right] \cdot\left[\begin{array}{c}
p_{\mathrm{v}}^{\mathrm{i}} \\
q_{\mathrm{v}}^{\mathrm{i}} \\
r_{\mathrm{v}}^{\mathrm{i}}
\end{array}\right]
$$

where $\left(x_{p}, x_{q}, x_{r}\right),\left(y_{p}, y_{q}, y_{r}\right)$ and $\left(z_{p}, z_{q}, z_{r}\right)$ are the direction cosines of the [100], [010], and [001] dendrite arms related to the coordinate $x, y$, and $z$ axes, respectively. $\left(p_{\mathrm{v}}^{\mathrm{i}}, q_{\mathrm{v}}^{\mathrm{i}}, r_{\mathrm{v}}^{\mathrm{i}}\right)$ are the direction cosines of the vector $\vec{L}_{v}^{i}$, related to the coordinate $x, y$, and $z$ axes, respectively. For a more detailed description of the growth algorithm, refer to Ref. 15). $V(\Delta T)$ is the growth rate of a dendrite tip at a certain undercooling, it can be calculated using the Lipton-Glicksman-Kurz (LGK) model. ${ }^{17)}$

For the equiaxed grain:

$$
V(\Delta T)=\mu^{*} \Delta T^{2}=\frac{2 \sigma^{*} \alpha c_{\mathrm{p}}}{\Gamma \Delta H} \Delta T^{2}
$$

where $\mu$ is growth kinetic parameter depended upon the properties of the metal, $\Delta H$ is latent heat, $c_{\mathrm{p}}$ is the heat capacity under constant pressure, $\sigma^{*}$ is the stable coefficient $\left(1 / 4 \pi^{2}\right), \Gamma$ is the Gibbs-Thomson coefficient, $\alpha$ is the thermal diffusibility.

For the columnar grain:

$$
V(\Delta T)=\frac{\lambda_{\mathrm{L}} G_{\mathrm{L}}-\lambda_{\mathrm{s}} G_{\mathrm{s}}}{\rho \Delta H}
$$

$\lambda_{\mathrm{s}}, \lambda_{\mathrm{L}}$ is the thermal conductivity, $G_{\mathrm{s}}, G_{\mathrm{L}}$ is the thermal gradient (s: solid, L: liquid).

Then, the solid fraction of the liquid cell $i$ at a certain time $f_{\mathrm{s}}^{\mathrm{i}}(t)$ can be expressed by:

$$
f_{\mathrm{s}}^{\mathrm{i}}(t)=\frac{L_{\mathrm{v}}^{\mathrm{i}}(t)}{L}
$$

where $L$ is the spacing between the cell $\mathrm{v}$ and liquid cell $\mathrm{i}$. When $f_{\mathrm{s}}^{\mathrm{i}}(t) \geqq 1$, which means that the growth front of the cell $\mathrm{v}$ can touch the center of the liquid cell $\mathrm{i}$, the liquid cell $i$ transforms its state from liquid to solid and adopts the same orientation index as that of cell $\mathrm{v}$.

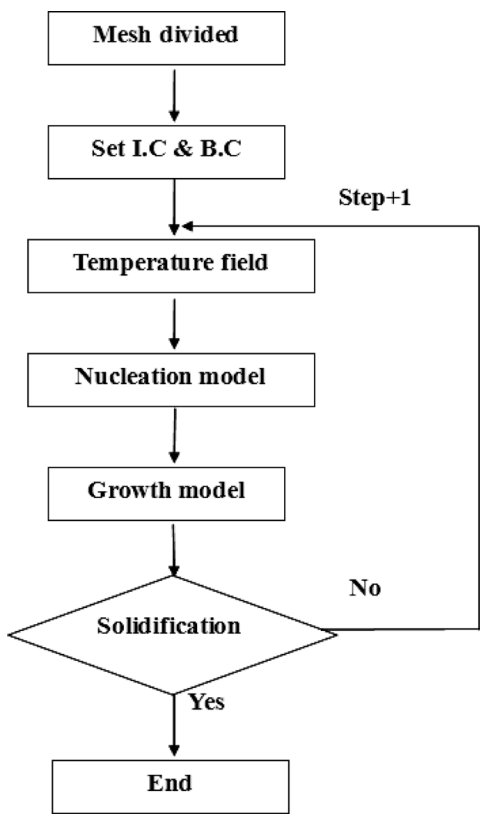

Fig. 5. Numerical simulation flowchart of microstructure modeling.

\subsection{Determination of the Time Step}

In order to reduce the computational time, two time steps were used; one for the macroscopic heat transfer calculation and the other for the microscopic CA calculation. macro time step:

$$
\delta t_{\mathrm{T}}=\frac{\Delta r^{2} \times \rho C_{\mathrm{p}}}{5 \times \lambda}
$$

micro time step:

$$
\delta t_{\mathrm{CA}}=\frac{d x}{5 \times V_{\max }}
$$

where $d x$ is the cell size and $V_{\max }$ is the maximum growth velocity obtained by scanning the growth velocities of all interface liquid cells during each time step.

The flowchart for the microstructure simulation of a pure copper rod under the VCC process is shown in Fig. 5. The simulation procedure using the coupled macro-micro model are as follows: firstly, the simulation system is initialized with the domain length, mesh size, and initial temperature; secondly, the energy equations in the liquid and the solid regions are solved; thirdly, whether a certain liquid cell nucleates or a certain solid cell grows with a certain growth velocity is estimated using the CA model based on the calculated temperature in the CA cells. At this stage, the liberation of latent heat in the solidifying cells is estimated using the temperature recovery method. Finally, using the updated temperature calculation for the new liquid region can be continued. This series of calculations is repeated until the end of solidification. The thermal and physical properties used in the present calculations are listed in Tables 2 and 3. The actual nucleation parameters are important and should be determined by the Differential Thermal Analyzer (DTA) experiment. However, in this study the most appropriate values to be used for the parameters were obtained from related papers as cited and then verified by the computer simulation results. These appropriate nucle- 
Table 2. Parameters for numerical simulation of VCC process.

\begin{tabular}{|c|c|c|c|}
\hline \multicolumn{2}{|l|}{ Pure copper } & \multicolumn{2}{|l|}{ Graphite mold } \\
\hline Fusion temp. $\left({ }^{\circ} \mathrm{C}\right)$ & 1083 & $\begin{array}{c}\text { Specific } \\
\text { heat }\left(\mathrm{J} / \mathrm{kg} \cdot{ }^{\circ} \mathrm{C}\right)\end{array}$ & 1020 \\
\hline $\begin{array}{c}\text { Thermal } \\
\text { conductivity } .\left(\mathrm{w} / \mathrm{m} \cdot{ }^{\circ} \mathrm{C}\right)\end{array}$ & 170 & Density $\left(\mathrm{kg} / \mathrm{m}^{3}\right)$ & 1793 \\
\hline Specific heat $\left(\mathrm{J} / \mathrm{kg} \cdot{ }^{\circ} \mathrm{C}\right)$ & 483 & \multirow{3}{*}{$\begin{array}{c}\text { Thermal } \\
\text { conductivity } .\left(\mathrm{w} / \mathrm{m} \cdot{ }^{\circ} \mathrm{C}\right)\end{array}$} & \multirow{3}{*}{140} \\
\hline Latent heat $(\mathrm{J} / \mathrm{kg})$ & 205000 & & \\
\hline Density $\left(\mathrm{kg} / \mathrm{m}^{3}\right)$ & 8920 & & \\
\hline
\end{tabular}

Table 3. Parameters for microstructure modeling of VCC process.

\begin{tabular}{|c|c|c|c|c|c|c|c|}
\hline $\begin{array}{l}\text { CA cell size } \\
\quad(\mu \mathrm{m})\end{array}$ & $\begin{array}{c}\text { Number of } \\
\text { cells in a } \\
\text { block }\end{array}$ & \multicolumn{6}{|c|}{ Number of crystallographic orientations } \\
\hline \multirow{4}{*}{40} & \multirow{4}{*}{$10 * 10 * 10$} & \multicolumn{6}{|c|}{64} \\
\hline & & \multicolumn{3}{|c|}{ Volume nucleation } & \multicolumn{3}{|c|}{ Surface nucleation } \\
\hline & & $\begin{array}{l}\Delta \mathrm{T}_{\mathrm{N}} \\
\left({ }^{\circ} \mathrm{C}\right)\end{array}$ & $\begin{array}{l}\Delta \mathrm{T}_{\sigma} \\
\left({ }^{\circ} \mathrm{C}\right)\end{array}$ & $\begin{array}{l}\mathrm{n}_{\max } \\
\left(\mathrm{m}^{-3}\right)\end{array}$ & $\begin{array}{l}\Delta \mathrm{T}_{\mathrm{N}} \\
\left({ }^{\circ} \mathrm{C}\right)\end{array}$ & $\begin{array}{l}\Delta \mathrm{T}_{\sigma} \\
\left({ }^{\circ} \mathrm{C}\right)\end{array}$ & $\begin{array}{c}\mathrm{n}_{\max } \\
\left(\mathrm{m}^{-2}\right)\end{array}$ \\
\hline & & 1.0 & 0.1 & $8.0^{*} 10^{10}$ & 0.1 & 0.1 & $1.8^{*} 10^{8}$ \\
\hline
\end{tabular}

ation parameters were obtained from Ref. 18). The simulated and experimentally observed microstructures were compared to examine the reliability of the proposed simulation technique.

\section{Results and Discussion}

The examination of the VCC process is described in two parts. In the first part, finite difference method is used to calculate the macroscopic temperature fields and CA method is used to compute microscopic nucleation and growth mechanism, thus, the macro and micro scale effects are coupled on the final microstructure. In the second part, the actual process of VCC is used to observe changes in the evolution mechanism of solidification microstructure with respect to casting speed.

\subsection{Temperature Distribution in VCC Process}

For macroscopic purpose of this study, finite difference methods were used to solve the two dimensional heat transfer equations. The resulting temperature distribution is shown in Fig. 6. The shape of the melt pool becomes sharper with increasing casting speed. Figure 7 shows that when casting speed is increased, the position of the $\mathrm{S} / \mathrm{L}$ interface moves closer to the exit of the mould $(0 \mathrm{~cm}$ is the top of the mould), which may cause the melted metal to leak. The symmetry in cylindrical coordinates allows the 2D temperature to be expanded to a 3-D temperature in the 3D-CA model to simplify the calculation of the simulation process and to speed up the calculation time. The 3-D macroscopic temperature field is used as the basis for the development of microscopic nucleation and growth models. As shown in Fig. 8, the integrated macro-micro model is used to obtain the temperature of CA cells by interpolating the macroscopic temperature field. The undercooling required for nucleation and growth model is then determined. The relative latent heat released during solidification is then fed back to the macroscopic temperature evaluation. The process is repeated until the solidification is finished. Casting speed is one of the main factors that affect the evolution of the solidification microstructure. Therefore, the results

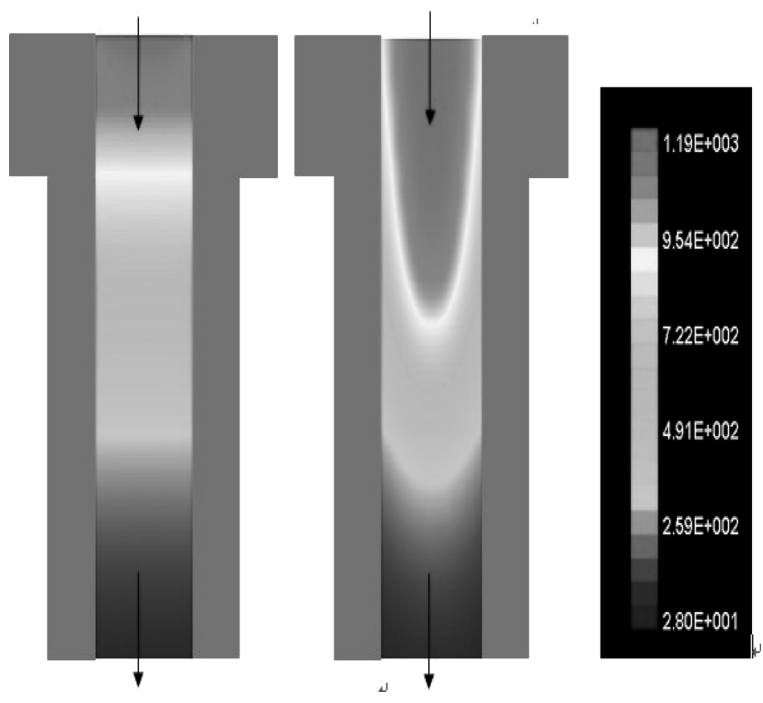

Fig. 6. Temperature distribution for casting speeds of (a) 100 and (b) $800 \mathrm{~mm} / \mathrm{min}$.

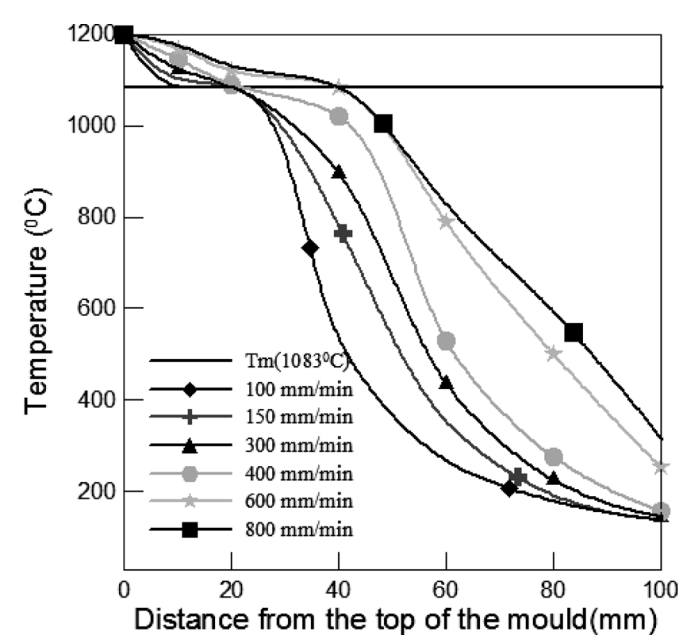

Fig. 7. Cooling curves of temperature profiles with distance for various casting speeds.

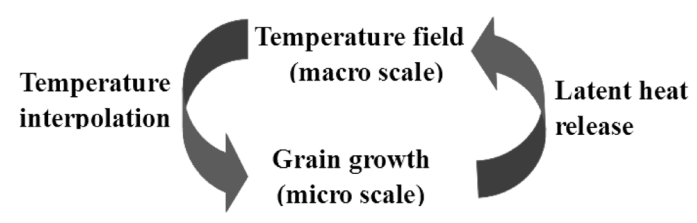

Fig. 8. Coupling mechanism of macro and micro scale models.

are divided into three parts. The first case is low casting speed (100 and $150 \mathrm{~mm} / \mathrm{min})$, the second case is middle casting speed (300 and $400 \mathrm{~mm} / \mathrm{min}$ ) and the third case is high casting speed (600 and $800 \mathrm{~mm} / \mathrm{min}$ ).

\subsection{Low Casting Speed in VCC Process}

Since a 3-D model requires large storage resources for proper results, it is beneficial to simplify the methodology and combine the results of two dimensional cross sections to create a three dimensional model. Figure 9 shows the microstructure obtained from casting with a $100 \mathrm{~mm} / \mathrm{min}$ casting speed and $20 \mathrm{~L} / \mathrm{min}$ flow rate of cooling water. Figures 9(a) and 9(b) show the simulation results of the transverse and longitudinal sections, respectively. In the trans- 


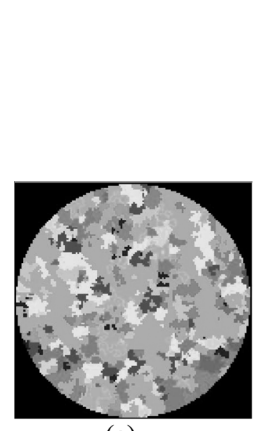

(a)
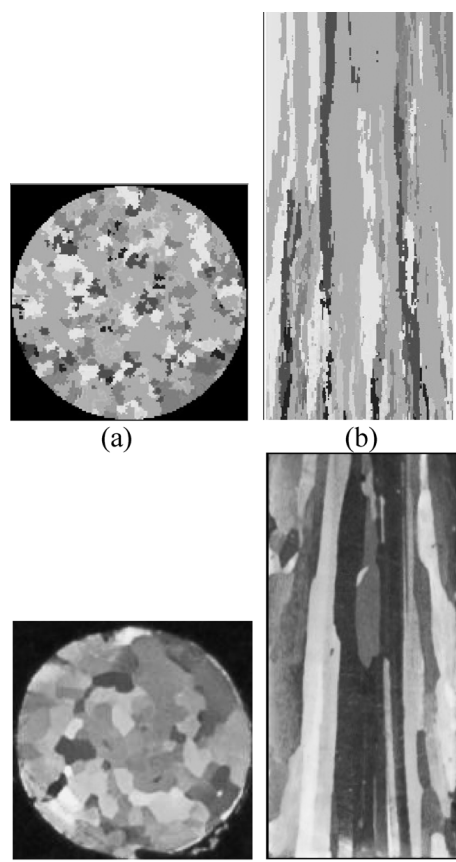

(c) (b)

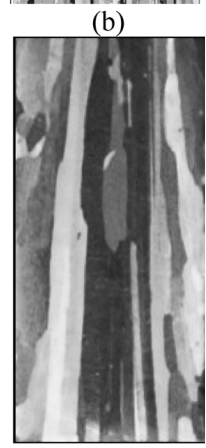

(d)
Fig. 9. Solidification microstructure of copper rod for a casting speed of $100 \mathrm{~mm} / \mathrm{min}$. (a) Simulated microstructure of the transverse section, (b) simulated microstructure of the longitudinal section, (c) observed metallography of the transverse section, and (d) observed metallography of the longitudinal section.

verse section, the major grain morphologies are circular and the grain sizes are about equal. In the longitudinal section, the grains all have a parallel columnar structure and the grain growth follows the axial direction, similar to that predicted from the temperature gradient direction. In order to verify the accuracy of the proposed microstructure prediction system, the results of the numerical simulation were compared with those of the actual casting experiment. Figures 9(c) and 9(d) show the metallography of the copper rod for a casting speed of $100 \mathrm{~mm} / \mathrm{min}$. In the two figures, the grains are circular and elongated, respectively. The results of the casting experiment are similar to those predicted in the numerical simulation (see Figs. 9(a) and 9(b)). However, the grain size of the experimental sample is bigger than that obtained using the simulation system.

Figure 10 shows the microstructure obtained with a $150 \mathrm{~mm} / \mathrm{min}$ casting speed and a cooling rate of $20 \mathrm{~L} / \mathrm{min}$. In Fig. 10(a), the grains are nearly circular and the grains are thicker than those in Fig. 9(a). In Fig. 10(b), the direction of grain growth is axial and the columnar grains are thicker than those in Fig. 9(b). This result could be attributed to a slower grain cooling rate caused by the increase in casting speed, leading to thicker grains. ${ }^{18)}$ Figures $10(\mathrm{c})$ and 10 (d) show the metallography for a $150 \mathrm{~mm} / \mathrm{min}$ casting speed. The grains are nearly circular and elongated, and the grains are bigger than those shown in Figs. 10(a) and 10(b). A smaller grain size was obtained in the simulation system due to the difference of values of the interfacial heat coefficient $\left(h_{\text {int }}\right)$ between metal and mould. The $h_{\text {int }}$ value should be a function of temperature, but a constant value is adopted in the present calculation. In the general solidification of casting, an air gap forms between the solidified

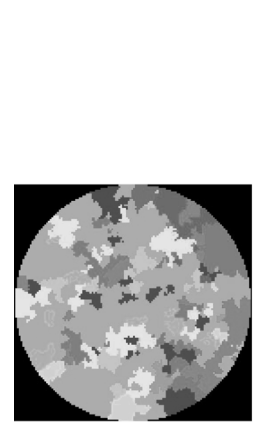

(a)

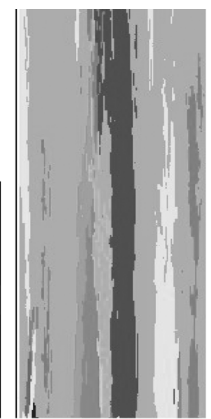

(b)

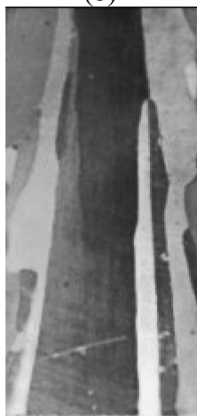

(d)
Fig. 10. Solidification microstructure of copper rod for a casting speed of $150 \mathrm{~mm} / \mathrm{min}$. (a) Simulated microstructure of the transverse section, (b) simulated microstructure of the longitudinal section, (c) observed metallography of the transverse section, and (d) observed metallography of the longitudinal section.

metal and mould. This air gap lowers the heat transfer between metal and mould, leading to an increased grain size. Figures 9(c) and 9(d) show the grains become thicker with increasing the casting speed.

\subsection{Middle Casting Speed in VCC Process}

Figure 11 shows the microstructure solidified under a $300 \mathrm{~mm} / \mathrm{min}$ casting speed. In the transverse section, two types of grain shape were obtained. Elongated grains were obtained on the wall of the mould and the circular grains were obtained in the central part of the mould. In the longitudinal section, the grains from the two sides of the mould are titled elongated and those in the central part are parallel elongated. Figures 11(c) and 11(d) show the metallography under a $300 \mathrm{~mm} / \mathrm{min}$ casting speed. In the transverse section, the grains on the wall of the mould are elongated and the grains in the central part of the mould are circular. In the longitudinal section, the grains are titled elongated and parallel elongated.

Figure 12 shows the microstructure of the copper rod for a casting speed of $400 \mathrm{~mm} / \mathrm{min}$. In the transverse and longitudinal sections, the grains are similar to those in Fig. 11, respectively. The numerical simulation results show that the microstructures of copper rods can be exactly predicted using the proposed simulation system.

\subsection{High Casting Speed in VCC Process}

In Fig. 13(a), where the casting speed is $600 \mathrm{~mm} / \mathrm{min}$, most grains are elongated, with a few being circular. In Fig. 13(b), the grains are nearly horizontal columnar and parallel columnar. In the simulation system, majority and plurality grains are elongated and a few grains are circular, as 


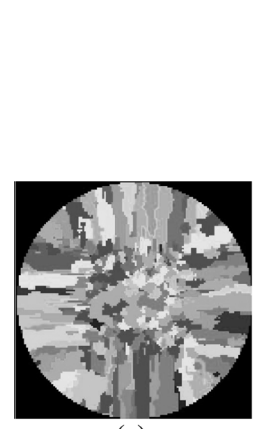

(a)

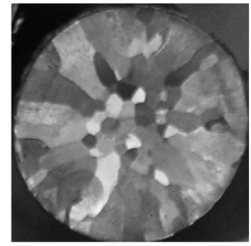

(c)

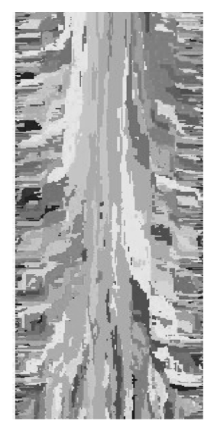

(b)

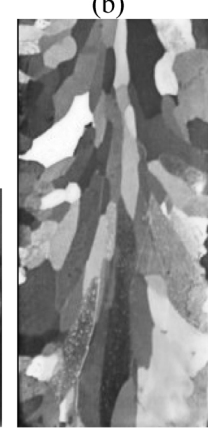

(d)

Fig. 11. Solidification microstructure of copper rod for a casting speed of $300 \mathrm{~mm} / \mathrm{min}$. (a) Simulated microstructure of the transverse section, (b) simulated microstructure of the longitudinal section, (c) observed metallography of the transverse section, and (d) observed metallography of the longitudinal section.

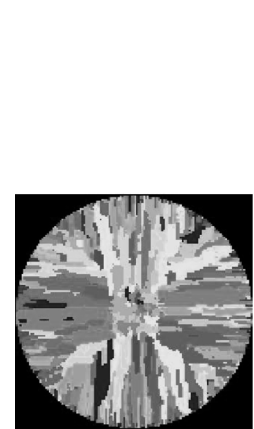

(a)

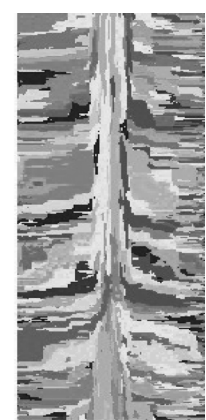

(b)

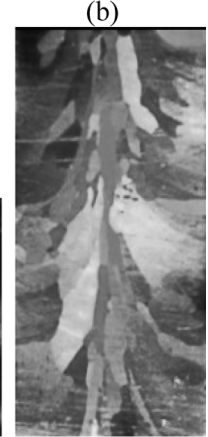

(d) (c)

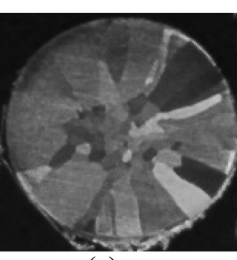

Fig. 12. Solidification microstructure of copper rod for a casting speed of $400 \mathrm{~mm} / \mathrm{min}$. (a) Simulated microstructure of the transverse section, (b) simulated microstructure of the longitudinal section, (c) observed metallography of the transverse section, and (d) observed metallography of the longitudinal section.

shown in Fig. 13(c), and most grains are horizontal columnar and parallel columnar, as shown in Fig. 13(d).

For a casting speed of $800 \mathrm{~mm} / \mathrm{min}$, shown in Figs. 14(a) and 14(b), all the grains are elongated in the transverse sec-

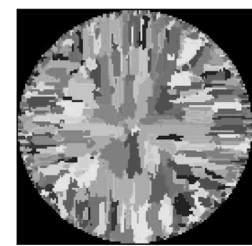

(a)

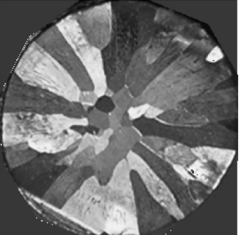

(c)

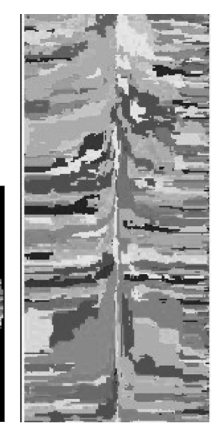

(b)

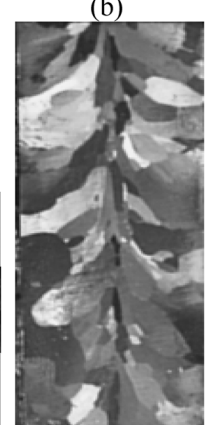

(d)
Fig. 13. Solidification microstructure of copper rod for a casting speed of $600 \mathrm{~mm} / \mathrm{min}$. (a) Simulated microstructure of the transverse section, (b) simulated microstructure of the longitudinal section, (c) observed metallography of the transverse section, and (d) observed metallography of the longitudinal section.

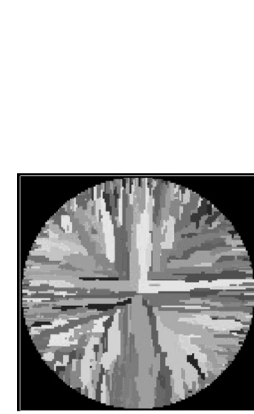

(a)

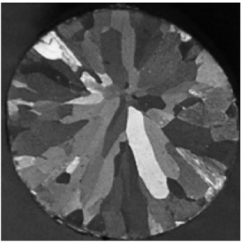

(c)

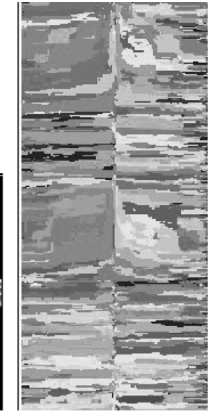

(b)

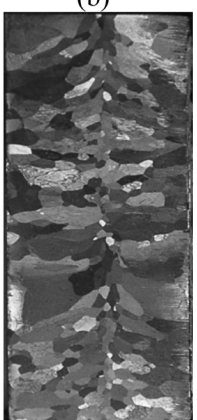

(d)
Fig. 14. Solidification microstructure of copper rod for a casting speed of $800 \mathrm{~mm} / \mathrm{min}$. (a) Simulated microstructure of the transverse section, (b) simulated microstructure of the longitudinal section, (c) observed metallography of the transverse section, and (d) observed metallography of the longitudinal section.

tion and horizontal columnar in the longitudinal section. The transformation of the solidification microstructure from the axial to the radial growth direction might be due to a change in the heat flux with increasing casting speed. The 
results were verified using observations in the macroscopic temperature field where the temperature gradient diverts from axial to radial directions. In Figs. 14(c) and 14(d), all the observed metallograph individually are elongated in the transverse section and horizontal columnar in the longitudinal section. The predictions of the solidification microstructures obtained using the proposed numerical simulation system based on a 3D-CA model are similar to the results of the actual casting experiment.

\section{Conclusions}

(1) The casting speed affects the evolution of solidification microstructure. There is a tendency for the grain growth direction to change from axial to radial with increasing casting speed.

(2) In the numerical simulation, the finite difference method and the 3D-CA model were used to obtain macroscopic temperature fields and the microscopic nucleation and growth process, respectively. The 3D-CA model effectively simulates the solidification microstructure of a pure copper rod during the VCC process.

\section{REFERENCES}

1) M. Kato: J. Miner. Met. Mater. Soc., 12 (1995), 44.

2) W. Oldfield: ASM Trans., 59 (1966), 945.

3) J. D. Hunt: Mater. Sci. Eng., 65 (1984), 75.

4) I. Dustin and W. Kurz: Z. Metallkd., 77 (1986), 265.

5) S. G. R. Brown and J. A. Spittle: Mater. Sci. Technol., 5 (1989), 362

6) C. A. Gandin and M. Rappaz: Acta Mater., 42 (1994), 2233.

7) C. A. Gandin, J. L. Desbiolles, M. Rappaz and P. Thevoz: Metall. Mater. Trans. A, 30 (1999), 3153.

8) M. Rappaz and C. A. Gandin: Acta Mater., 41 (1993), 345.

9) M. Rappaz, C. A. Gandin, J. L. Desbiolles and P. Thevoz: Metall. Mater. Trans. A, 27 (1996), 695.

10) M. F. Zhu and C. P. Hong: Metall. Mater. Trans. A, 35 (2004), 1555.

11) H. B. Dong and P. D. Lee: Acta Mater, 53 (2005), 659.

12) Y. Natsume and K. Ohsasa: ISIJ Int., 46 (2006), 896.

13) G. Guillemot, C. A. Gandin and M. Bellet: J. Cryst. Growth, 303 (2007), 58

14) Z. M. Xu, G. X. Geng and J. G. Li: J. Shanghai Jiao Tong Univ., 35 (2001), 406.

15) Y. H. Chang, S. M. Lee, K. Y. Lee and C. P. Hong: ISIJ Int., 38 (1998), 63.

16) M. F. Zhu and C. P. Hong: ISIJ Int., 42 (2002), 520.

17) J. Lipton, M. E. Glicksman and W. Kurz: Metall. Mater. Trans. A, 18 (1987), 341.

18) Y. T. Ding and G. G. Xu: Foundry Technol., 26 (2005), 1075. 